\title{
Annual Report of the Korean Association of External Quality Assessment Service on Urinalysis and Fecal Occult Blood Testing (2018)
}

Chang-Ho Jeon, A-Jin Lee, Sang-Gyung Kim, Hun-Seok Suh, and Young-Cheol Bae Department of Laboratory Medicine, School of Medicine, Catholic University of Daegu, Daegu, Korea

Corresponding author: Chang-Ho Jeon Department of Laboratory Medicine, Daegu Catholic University Medical Center, School of Medicine, Catholic University of Daegu, 33 Duryugongwon-ro 17-gil, Namgu, Daegu 42472, Korea Tel: +82-53-650-4144 Fax: +82-53-653-8672

E-mail: chjeon@cu.ac.kr
In 2018, external quality assessment trials for urinalysis and fecal occult blood (FOB) were performed using 1,590 participants. Urine chemistry tests were performed thrice while urine sediment and FOB tests twice. Urine chemistry tests comprised of $\mathrm{pH}$, protein, glucose, ketone body, bilirubin, blood, urobilinogen, nitrite, leukocyte, and specific gravity analyses. The results of urine chemistry and specific gravity tests showed accuracy rates $>95 \%$, except for the $\mathrm{pH}$ test. The accuracy rate of urine sediments was low, especially for atypical calcium oxalate crystal and red blood cell cast. In the FOB quality test, reagents showed accuracy rates $>90 \%$, except for SD and GC Genedia FOB reagents. In the FOB quantitative test, Alfresa NS-Plus C instrument showed falsely high values in the FOB negative specimens.

(J Lab Med Qual Assur 2019;41:75-81)

Key Words: Quality control, Urinalysis, Occult blood, Accuracy

\section{서론}

요경검학분과의 2018년도 외부정도관리사업을 위하여 요화 학검사는 3 회 시행하였고 총 12 개의 관리물질을 사용하였다. 요침사검사는 2 회 시행하였으며 총 8 개의 사진을 게시하여 판 독하도록 하였다. 대변잠혈검사(fecal occult blood, FOB) 또 한 2회 시행하였으며 총 6 개의 관리물질을 사용하였다. 요화 학검사 및 $\mathrm{FOB}$ 신빙도조사에는 국내에서 제조된 관리물질을 사용하였다.

2018년 신빙도조사사업 결과판정에서 반정량결과를 나타내 는 검사항목은 결과값이 최빈도값 \pm 1 단계를 보이는 전체 기
관 수가 전체 참여기관 수의 $80 \%$ 를 넘으면 정답으로 판정하 였다. 2018년도 이전에는 특정 장비의 결과분포가 전체 결과 분포와 상이하게 나타날 경우 다빈도 결과는 정답으로 반영하 였으나 일관된 규정을 적용하기 어려웠다. 따라서 2018년에는 상기와 같이 전체 참여기관 수의 $80 \%$ 를 넘으면 정답으로 판 정하였다. 참여기관은 1 차 $1,490,2$ 차 $1,559,3$ 차 1,590 기관이 각각 참여하여 2017년에 비하여 증가하였다. 


\section{Journal of LABORATORY MEDICINE and QUALITY ASSURANCE}

\section{Chang-Ho Jeon et al • External Quality Assessment in Urinalysis}

\section{재료 및 방법}

\section{1. 대상}

요경검학분과에서는 대한임상검사정도관리협회에 등록된 기관을 대상으로 2018년도 2월, 4월, 8월 3차에 걸쳐 정도관리 물질을 발송하였다. 참여기관 수는 3 차 조사에서 1,590 기관으 로 2017년도 동일 차수의 1,450 기관에 비하여 $9.6 \%$ 증가되었 다.

\section{2. 재료}

요화학검사를 위한 관리물질은 1차(CU-18-01-04), 2차 (CU-18-05-08), 3차(CU-18-09-12) 검체 모두 국내에서 제조한 액상관리물질 4종씩을 각 회원기관에 냉장 포장하여 발송하였다. 이 중 1 차 및 3 차에는 본 협회 홈페이지에 게시한 요침사 사진 8 매 등 모두 20 종의 검체를 우송 및 게시하여 정 도관리 신빙도조사를 시행하였다. 결과치의 입력은 본 협회에 서 구축한 신빙도조사사업 홈페이지에서 직접 입력하는 방식 을 사용하였다. $\mathrm{FOB}$ 를 위한 관리물질도 1차 및 2차 검체 모 두 국내에서 제조한 점액성 분말관리물질 3종(CS-17-01-06) 을 각 회원기관에 냉장 포장하여 발송하였다.

\section{3. 정도관리물질의 허용치}

요화학 및 $\mathrm{FOB}$ 검사의 경우 분과위원회에서 실험한 참고 치, 각 기관에서 회신한 결과의 일치도를 고려하였으며, 정성 결과는 정답이거나 참여기관의 $80 \%$ 일치를 보이는 결과로 하 였다. 반정량결과는 결과값이 최빈도값 \pm 1 단계를 보이는 전체 기관 수가 전체 참여기관 수의 $80 \%$ 를 넘으면 정답으로 판정 하였다. 정량결과를 보이는 검사항목은 결과값이 기준분류에 대해 3 표준편차지수(standard deviation index) 이내일 경우 정답으로 판정하였다.

\section{결과}

\section{1. 요화학검사 9종의 신빙도조사 성적}

요화학검사 9종 $(\mathrm{pH}$, protein, glucose, ketone, bilirubin, blood, urobilinogen, nitrite, leukocyte)의 신빙도조사 성적은 Table 1에 요약하였다. 모든 항목에서 $95 \%$ 이상의 정답률을 나타내었으나 $\mathrm{pH}$ 항목은 1-3차 모두 $95 \%$ 이하의 정답률을 나 타내었다.

\section{2. 요화학 분석기에 따른 요화학검사 신빙도조사 성적}

각 회사별 요화학 분석기에 따른 요화학검사의 신빙
도조사 성적은 Table 2와 같다. YD (YD Diagnostics, Yongin, Korea)가 $39.8 \%$ 로 가장 많이 사용하고 있으며, SD (Standard Diagnostics, Seoul, Korea) 21.8\%, Roche (Roche Diagnostics, Mannheim, Germany) 14.8\%, DFI (DFI Co. Ltd., Gimhae, Korea) 9.6\% 순이었다.

대부분의 장비에서 $90 \%$ 이상의 정답률을 보였으나 회사 별 장비에 따라 정답률에 다소 차이를 나타내어 일부 검사항 목에서는 $90 \%$ 이하의 정답률을 보였다. $\mathrm{pH}$ 항목은 Roche, Siemens (Siemens Healthcare, Erlangen, Germany), 및 Eiken (Eiken Chemical Co., Tokyo, Japan) 제품이 90\% 이하의 정답률을 나타내었고, protein은 DFI사, ketone은 Sysmex사, bilirubin은 Beckman사(Beckman Coulter Inc., Brea, CA, USA), blood는 Sysmex 및 Arkray사(Arkray Inc., Kyoto, Japan), leukocyte은 Beckman사에서 각각 90\% 이하의 정답률을 나타내었다.

$\mathrm{pH}$ 항목에서 $90 \%$ 이하를 보이는 시약들이 많아서 1-3회차 검체 중 가장 정답률이 낮은 검체를 대상으로 결과분포를 분석 하였다(Table 3). 최빈도값 \pm 1 단계 값이 검체 CU-18-01에서 는 $90.5 \%$, 검체명 CU-18-05에서는 $89.7 \%$, 검체 CU-18- 11 에서는 84.5\%로 나타났다. CU-18-01 및 CU-18-05 검체는 최빈도값 \pm 1 단계를 벗어나는 기관의 비율이 다른 검체에 비 해 상대적으로 많았다. CU-18-11 검체는 최빈도값이 5.0으로 5.5 까지만 정답으로 인정되어 가장 낮은 정답률을 나타내었 다. 정답률이 낮았던 3 개 회사의 결과를 분석한 결과 CU-18-

Table 1. Number of participants and acceptable rates in urine chemistry quality control

\begin{tabular}{|c|c|c|c|c|c|c|}
\hline \multirow[b]{2}{*}{ Tests } & \multicolumn{2}{|c|}{ 1st QC } & \multicolumn{2}{|c|}{ 2nd QC } & \multicolumn{2}{|c|}{ 3rd QC } \\
\hline & $\begin{array}{l}\text { Parti- } \\
\text { cipants }\end{array}$ & $\begin{array}{c}\text { Accept- } \\
\text { able } \\
(\%)\end{array}$ & $\begin{array}{l}\text { Parti- } \\
\text { ci- } \\
\text { pants }\end{array}$ & $\begin{array}{c}\text { Accept- } \\
\text { able } \\
(\%)\end{array}$ & $\begin{array}{l}\text { Parti- } \\
\text { ci- } \\
\text { pants }\end{array}$ & $\begin{array}{l}\text { Accept- } \\
\text { able (\%) }\end{array}$ \\
\hline $\mathrm{pH}$ & 1,490 & 94.0 & 1,558 & 93.2 & 1,589 & 90.4 \\
\hline Protein & 1,495 & 96.5 & 1,564 & 94.7 & 1,595 & 97.9 \\
\hline Glucose & 1,490 & 98.2 & 1,559 & 98.1 & 1,590 & 99.2 \\
\hline Ketone & 1,451 & 99.5 & 1,516 & 99.6 & 1,545 & 97.4 \\
\hline Bilirubin & 1,449 & 98.9 & 1,514 & 99.3 & 1,543 & 98.3 \\
\hline Blood & 1,490 & 98.2 & 1,559 & 97.3 & 1,590 & 95.1 \\
\hline $\begin{array}{l}\text { Urobili- } \\
\text { nogen }\end{array}$ & 1,451 & 99.0 & 1,516 & 97.6 & 1,545 & 94.2 \\
\hline Nitrite & 1,427 & 99.6 & 1,484 & 99.6 & 1,509 & 99.3 \\
\hline $\begin{array}{l}\text { Leuko- } \\
\text { cyte }\end{array}$ & 1,418 & 97.0 & 1,473 & 98.9 & 1,497 & 99.0 \\
\hline
\end{tabular}

Abbreviation: QC, quality control. 
Journal of LABORATORY MEDICINE and QUALITY ASSURANCE

Chang-Ho Jeon et al • External Quality Assessment in Urinalysis

Table 2. Acceptable rates based on urine analyzers of different companies

\begin{tabular}{lcccccccccc}
\hline Instrument & $\mathrm{pH}$ & Protein & Glucose & Ketone & Bilirubin & Blood & $\begin{array}{c}\text { Urobili- } \\
\text { nogen }\end{array}$ & Nitrite & $\begin{array}{c}\text { Leuko- } \\
\text { cyte }\end{array}$ & $\begin{array}{c}\text { Total } \\
\text { YD }\end{array}$ \\
SD & 92.7 & 97.4 & 98.4 & 99.5 & 99.5 & 98.7 & 99.6 & 99.7 & 97.8 & $580(39.8)$ \\
Roche & 95.6 & 97.6 & 98.7 & 99.5 & 99.5 & 97.3 & 98.9 & 99.3 & 99.0 & $318(21.8)$ \\
DFI & 91.8 & 98.0 & 99.9 & 99.2 & 99.7 & 96.6 & 95.4 & 99.2 & 99.4 & $216(14.8)$ \\
Siemens & 91.3 & 87.2 & 97.1 & 99.0 & 99.2 & 99.4 & 99.4 & 99.8 & 99.2 & $140(9.6)$ \\
Eiken & 87.3 & 93.8 & 98.8 & 92.3 & 93.0 & 91.9 & 98.1 & 99.7 & 99.1 & $49(3.4)$ \\
Sysmex & 99.6 & 94.5 & 100 & 89.0 & 98.3 & 89.2 & 99.1 & 99.8 & 95.5 & $32(2.2)$ \\
Arkray & 95.1 & 99.3 & 100 & 99.3 & 100 & 83.1 & 100 & 99.3 & 98.6 & $24(1.6)$ \\
Beckman & 99.0 & 93.3 & 93.3 & 99.0 & 83.7 & 93.3 & 99.0 & 99.0 & 89.7 & $9(0.6)$ \\
\hline
\end{tabular}

Values are presented as \% or number (\%).

The instruments were from the following companies: YD (YD Diagnostics, Yongin, Korea), SD (Standard Diagnostics, Seoul, Korea), Roche (Roche Diagnostics, Mannheim, Germany), DFI (DFI Co. Ltd., Gimhae, Korea), Siemens (Siemens Healthcare, Erlangen, Germany), Eiken (Eiken Chemical Co., Tokyo, Japan), Symex (Symex Co., Kobe, Japan), Arkray (Arkray Inc., Kyoto, Japan), and Beckman (Beckman Coulter Inc., Brea, CA, USA).

Table 3. Distribution of $\mathrm{pH}$ across specimens and instruments

\begin{tabular}{llcrrrc}
\hline Specimen & $\begin{array}{l}\text { Intended } \\
\text { response }\end{array}$ & $\begin{array}{c}\text { Re- } \\
\text { sult }\end{array}$ & $\begin{array}{c}\text { No. of } \\
\text { all }\end{array}$ & $\begin{array}{c}\text { No. } \\
\text { of } \\
\text { Eiken }\end{array}$ & $\begin{array}{c}\text { No. of } \\
\text { Roche }\end{array}$ & $\begin{array}{c}\text { No. of } \\
\text { Sie- } \\
\text { mens }\end{array}$ \\
\hline CU-18-01 & Unacceptable & $<5.5$ & 25 & 1 & 0 & 0 \\
& Unacceptable & 6 & 62 & 11 & 0 & 1 \\
& Acceptable & 6.5 & 235 & 12 & 2 & 1 \\
& Acceptable & 7 & 966 & 24 & 165 & 32 \\
& Acceptable & 7.5 & 148 & 1 & 5 & 47 \\
& Unacceptable & $>8$ & 54 & 0 & 44 & 0 \\
& Unacceptable & $<5.5$ & 32 & 0 & 1 & 1 \\
& Unacceptable & 6 & 54 & 11 & 0 & 1 \\
& Acceptable & 6.5 & 230 & 12 & 0 & 1 \\
& Acceptable & 7 & 1013 & 25 & 145 & 34 \\
& Acceptable & 7.5 & 155 & 1 & 8 & 44 \\
& Unacceptable & $>8$ & 74 & 0 & 63 & 1 \\
\hline \multirow{7}{*}{ CU-18-11 } & Acceptable & 5 & 974 & 43 & 202 & 10 \\
& Acceptable & 5.5 & 368 & 3 & 3 & 46 \\
& Unacceptable & 6 & 211 & 1 & 2 & 33 \\
& Unacceptable & $>6.5$ & 36 & 0 & 8 & 0 \\
\hline
\end{tabular}

The instruments were from the following companies: Eiken (Eiken Chemical Co., Tokyo, Japan), Roche (Roche Diagnostics, Mannheim, Germany), and Siemens (Siemens Healthcare, Erlangen, Germany).

01 및 CU-18-05 검체에서 Eiken사는 낮은 쪽으로 Roche 제 품은 높은 결과가 많았다. 반면 Siemens사는 CU-18-11 검체 에서 높은 결과가 많았다.
Table 4. Acceptable rates in the urine specific gravity test

\begin{tabular}{lcrcc}
\hline Specimen & $\begin{array}{c}\text { Partici- } \\
\text { pants }\end{array}$ & $\begin{array}{c}\text { Mean } \pm \text { standard } \\
\text { deviation }\end{array}$ & $\begin{array}{c}\text { 95\% } \\
\text { Confidence } \\
\text { interval }\end{array}$ & $\begin{array}{c}\text { Accept- } \\
\text { able } \\
\text { (\%) }\end{array}$ \\
\hline CU-18-01 & 1,417 & $1.006 \pm 0.003$ & 1.000 to 1.015 & 99.6 \\
CU-18-02 & 1,418 & $1.008 \pm 0.003$ & 1.005 to 1.015 & 97.6 \\
CU-18-03 & 1,417 & $1.008 \pm 0.003$ & 1.005 to 1.015 & 96.3 \\
CU-18-04 & 1,418 & $1.02 \pm 0.005$ & 1.010 to 1.030 & 97.9 \\
CU-18-05 & 1,476 & $1.006 \pm 0.003$ & 1.000 to 1.015 & 99.9 \\
CU-18-06 & 1,478 & $1.007 \pm 0.003$ & 1.005 to 1.014 & 96.2 \\
CU-18-07 & 1,478 & $1.007 \pm 0.026$ & 1.005 to 1.015 & 96.8 \\
CU-18-08 & 1,478 & $1.02 \pm 0.005$ & 1.010 to 1.030 & 97.7 \\
CU-18-09 & 1,502 & $1.006 \pm 0.003$ & 1.000 to 1.010 & 97.5 \\
CU-18-10 & 1,502 & $1.007 \pm 0.037$ & 1.005 to 1.015 & 97.7 \\
CU-18-11 & 1,502 & $1.003 \pm 0.036$ & 1.000 to 1.010 & 99.2 \\
CU-18-12 & 1,502 & $1.02 \pm 0.037$ & 1.010 to 1.030 & 98.1 \\
\hline
\end{tabular}

\section{3. 요화학 분석기로 시행한 요비중검사 신빙도조사 성적}

요비중검사는 굴절계 검사는 시행하지 않고 요화학 분석장 비로 측정하였다. Table 4 에서와 같이 모든 검체에서 $95 \%$ 이 상의 정답률을 나타내었다. 그러나 결과입력 시 잘못된 값이 입력되는 경우가 발생하여 $0.02,6.5$ 등의 결과가 입력되었다. 각 기관에서 결과입력 시 주의가 필요하였다.

\section{4. 사진 검체를 이용한 요침사물 검사결과}

사진 검체를 사용하여 시행한 요침사물 신빙도조사의 평 균 정답률은 $52.9 \%$ 에서 $99.6 \%$ 의 정답률을 보였다(Figs. 1,2 
and Table 5). Cholesterol 결정(CUI-18-03), 정자(CUI-1804), bilirubin 결정(CUI-18-06) 및 백혈구(CUI-18-07)는 모 두 $90 \%$ 이상의 정답률을 나타내었다.

Calcium oxalate (CUI-18-01)를 44.3\%에서 triple phosphate 결정으로 보고하였는데, 비정형 calcium oxalate 결정이라 판독이 용이하기 않았다. 세포원주(CUI-18-02)를 $21.1 \%$ 에서 과립원주로, 적혈구 원주(CUI- $18-05)$ 를 $42.5 \%$ 에 서 굵은 과립원주로 판정하여 모두 정답으로 채택하였다.

세뇨관상피세포(CUI-18-08)는 55.2\%에서 이행상피세포로 보고하여 정답으로 채택하였다. 두 세포는 매년 출제되지만 구 별이 용이하지 않았다. 한 장의 사진으로 판독이 어렵지만 요 침사물의 정확한 판독을 위하여 각 기관의 지속적인 관심과 노 력이 필요하였다.

\section{FOB 시약에 따른 $\mathrm{FOB}$ 정성검사의 정답률 및 시약의 분포}

$\mathrm{FOB}$ 시약에 따른 $\mathrm{FOB}$ 정성검사의 정답률은 Table 6 에 나타내었다. 시약은 SD FOB rapid test (335기관), YD FOB test (145기관), Asan FOB easy test (Asan Pharmaceutical, Seoul, Korea; 63기관), Eiken homocatch light (Eiken Chemical Co., Tokyo, Japan; 59기관) 순으로 사용하였다.

모든 시약에서 양호한 정답률을 나타내었으나, $\mathrm{FOB}$ 음성 3검체 중 2검체에서 SD FOB 및 GC Genedia FOB (Green Cross Medial Science Co., Yongin, Korea) 시약은 90\% 이 하의 낮은 정답률을 나타내었다. Humasis사 시약은 2017년 에는 음성 검체 2 개에서 모두 $90 \%$ 이하의 정답률을 나타내었 으나 2018년에는 $90 \%$ 이상의 정답률을 나타내었다.

\section{6. $\mathrm{FOB}$ 시약에 따른 $\mathrm{FOB}$ 정량검사의 정답률 및 시약의 분포}

$\mathrm{FOB}$ 정량검사결과 분포는 Table 7에 요약하였다. 장비 별로 검사에 사용하는 대변량이 달라서 장비 간 비교가 어려 워 보정한 값을 함께 비교하였다. 사용장비는 Eiken (161기 관), Alfresa (Alfresa Pharma Co., Osaka, Japan; 64기관), Kyowa (Kyowa Chemical Industry Co., Kagawa, Japan; 36 기관) 순으로 분포하였다. Alfresa 장비는 장비에 따라 결 과치가 너무나 상이하여 NS-Plus C와 NS-Prime으로 나누어 분석하였다.

Eiken, Kyowa, Alfresa NS-Prime 장비는 Kyowa 장비가
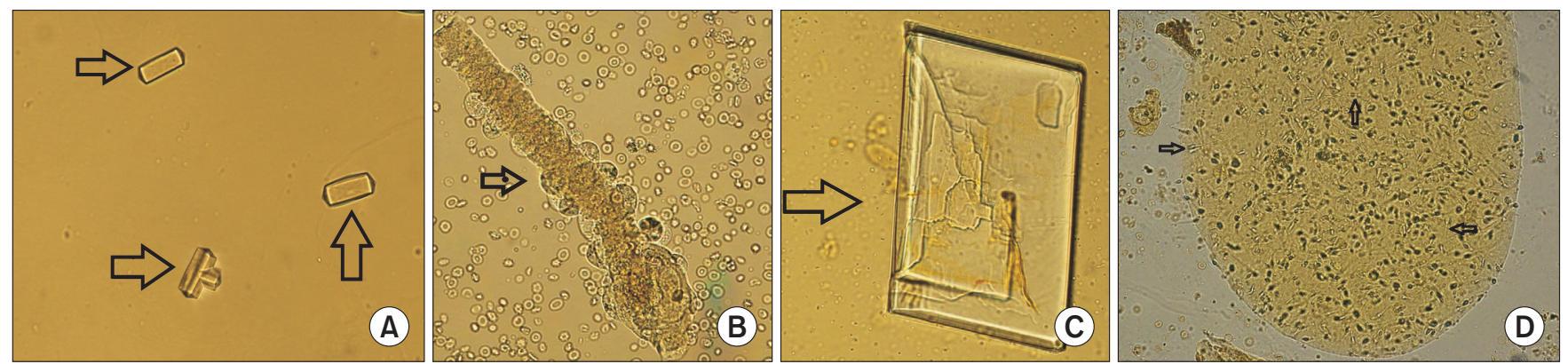

Fig. 1. Images of urine sediments (arrow) for external quality assessment. (A) CUI-18-01 calcium oxalate crystal (original magnification $\times 400)$. (B) CUI-18-02 cellular cast (original magnification $\times 200)$. (C) CUI-18-03 cholesterol crystal (original magnification $\times 400$ ). (D) CUI-18-04 spermatozoa (original magnification $\times 400$ ).
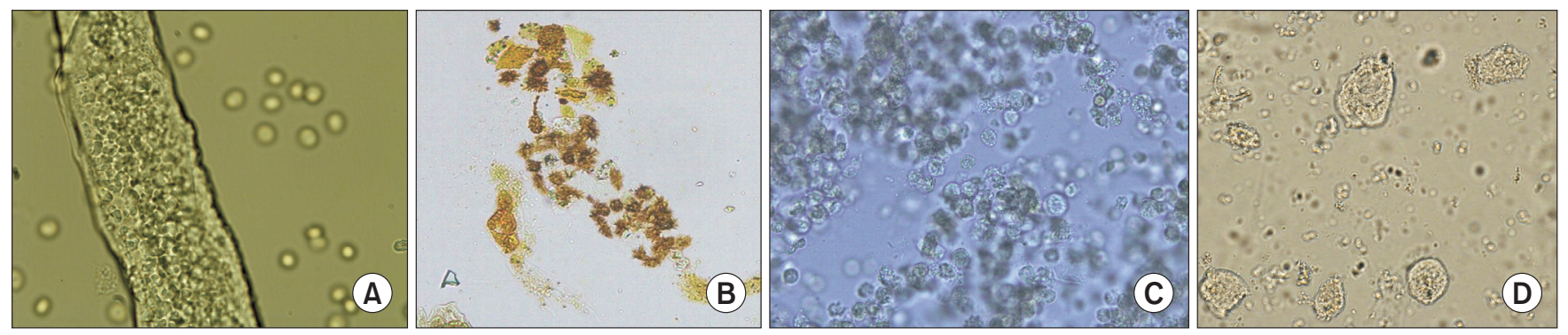

Fig. 2. Images of urine sediments for external quality assessment. (A) CUI-18-05 red blood cell cast (original magnification $\times 400$ ). (B) CUI-18-06 bilirubin crystal (original magnification $\times 100$ ). (C) CUI-18-07 white blood cells (original magnification $\times 200$ ). (D) CUI-18-08 renal tubular epithelial cells (original magnification $\times 400$ ). 
Journal of LABORATORY MEDICINE and QUALITY ASSURANCE

Chang-Ho Jeon et al • External Quality Assessment in Urinalysis

Table 5. Acceptable rates in the urine sediment examination

\begin{tabular}{|c|c|c|c|c|c|}
\hline Specimen no. & $\begin{array}{c}\text { No. of } \\
\text { participants }\end{array}$ & Results & No. of answers & $\begin{array}{c}\text { Acceptable } \\
(\%)\end{array}$ & $\begin{array}{c}\text { Unacceptable } \\
(\%)\end{array}$ \\
\hline CUI-18-01 & 924 & Calcium oxalate & 489 & 52.9 & \\
\hline CUI-18-02 & 924 & Cellular cast (RTE and/or neutrophil) & 561 & 60.7 & \\
\hline CUI-18-02 & 924 & Granular cast coarsely & 195 & 21.1 & \\
\hline CUI-18-03 & 924 & Cholesterol & 872 & 94.4 & \\
\hline CUI-18-03 & 924 & Uric acid & 50 & & 5.4 \\
\hline CUI-18-04 & 924 & Spermatozoa & 920 & 99.6 & \\
\hline CUI-18-05 & 901 & Granular cast coarsely & 383 & 42.5 & \\
\hline CUI-18-07 & 901 & Leukocyte (eosinophil, lymphocyte) & 884 & 98.1 & \\
\hline CUI-18-08 & 901 & Transitional epithelial cell (urothelial) & 497 & 55.2 & \\
\hline CUI-18-08 & 901 & Renal tubular epithelial cell (RTE) & 329 & 36.5 & \\
\hline CUI-18-08 & 901 & Squamous epithelial cell & 42 & & 4.7 \\
\hline
\end{tabular}

Abbreviations: RTE, renal tubular epithelial; RBC, red blood cell.

Table 6. Acceptable rates in the fecal occult blood quality test

\begin{tabular}{|c|c|c|c|c|c|c|c|}
\hline \multirow{2}{*}{ Reagents } & \multirow{2}{*}{ No. } & CS-18-01 & CS-18-02 & CS-18-03 & CS-18-04 & CS-18-05 & CS-18-06 \\
\hline & & Negative (\%) & Negative (\%) & Positive (\%) & Positive (\%) & Negative (\%) & Positive (\%) \\
\hline SD FOB rapid test & 335 & 84.7 & 97.1 & 99.8 & 100.0 & 76.4 & 100.0 \\
\hline YD Occult Tech FOB test & 145 & 94.9 & 100.0 & 100.0 & 100.0 & 93.8 & 98.6 \\
\hline ASAN easy test FOB & 63 & 98.2 & 100.0 & 100.0 & 100.0 & 92.1 & 98.4 \\
\hline Eiken Hemocatch light & 59 & 100.0 & 100.0 & 100.0 & 100.0 & 100.0 & 100.0 \\
\hline Humasis FOB test & 42 & 92.5 & 97.5 & 100.0 & 100.0 & 90.5 & 97.6 \\
\hline HBI HiSens FOB NCard & 34 & 100.0 & 100.0 & 100.0 & 100.0 & 91.2 & 97.1 \\
\hline GC Genedia FOB & 28 & 89.3 & 92.9 & 100.0 & 100.0 & 85.7 & 100.0 \\
\hline Bio focus FOB rapid test & 26 & 92.6 & 96.3 & 100.0 & 100.0 & 92.3 & 100.0 \\
\hline
\end{tabular}

Abbreviation: FOB, faecal occult blood.

The instruments used were from the following companies: SD (Standard Diagnostics, Seoul, Korea), YD (YD Diagnostics, Yongin, Korea), Asan Pharmaceutical (Seoul, Korea), Eiken Chemical Co. (Tokyo, Japan), Humasis Co. (Anyang, Korea), HBI Co. (Anyang, Korea), GC (Green Cross Medial Science Co., Yongin, Korea), and Bio Focus Co. (Uiwang, Korea).

FOB 양성 검체(CS-18-03, CS-18-04)에서 다소 높은 값을 보였으나 유사한 결과를 나타내었다. 그러나 Alfresa NS-Plus C 장비는 CS-18-01, CS-18-02 및 CS-18-05 검체에서 매우 높은 수치를 보였다. 본 검체들은 모두 음성 검체로서 Alfresa NS-Plus C를 사용하는 기관에서는 양성으로 보고할 수 있었 다.

www.jlmqa.org J Jab Med Qual Assur 2019;41:75-81

\section{고찰}

2018년은 2017년도에 이어서 참여기관이 지속적으로 증가 하였다. 2017년은 2016년도에 비해 10.7\%, 2018년은 2017년 도에 비해 $9.6 \%$ 의 증가를 각각 보였다.

신빙도조사 결과를 분석해 볼 때 2017년는 요화학검사 전 항목에서 95\% 이상의 정답률을 나타내었으나[1], 2018년에는 
Journal of LABORATORY MEDICINE and QUALITY ASSURANCE

Chang-Ho Jeon et al • External Quality Assessment in Urinalysis

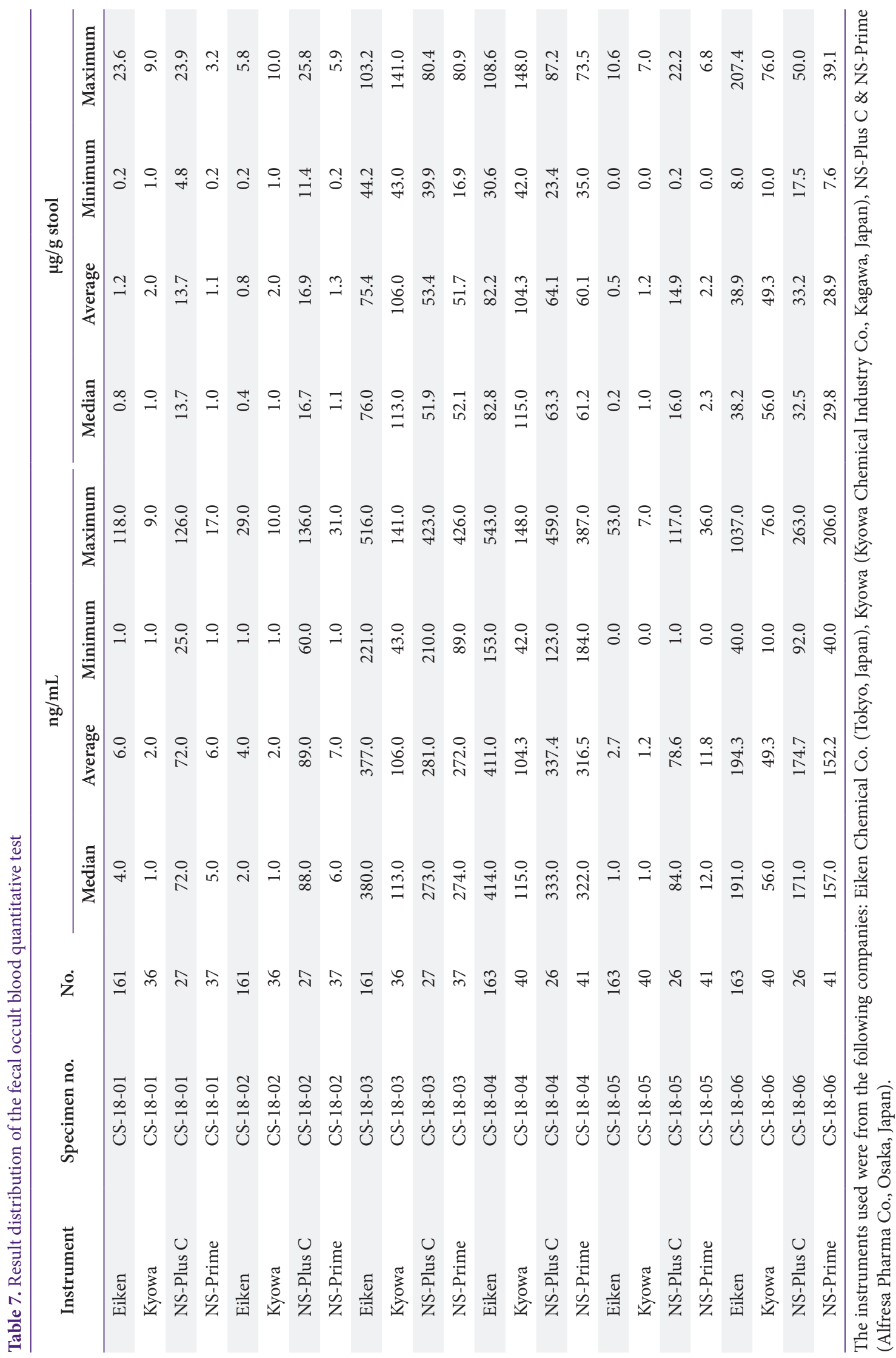




\title{
Journal of LABORATORY MEDICINE and QUALITY ASSURANCE
}

\author{
Chang-Ho Jeon et al • External Quality Assessment in Urinalysis
}

$\mathrm{pH}$ 항목이 $90.4 \%$ 의 정답률을 보여 다소 낮아진 정답률을 나 타내었다. 장비별로 분석한 요화학검사의 정답률에서는 $\mathrm{pH}$, protein, ketone, bilirubin, blood 및 leukocyte에서 90\% 이 하의 정답률을 나타내는 장비가 발견되었다. 이와 같이 다수의 항목에서 정답률이 낮아진 것은 반정량 값의 정답 허용범위를 전체 참여기관의 $80 \%$ 까지 적용하였기 때문이다. Table 3에서 와 같이 특정 장비의 결과분포가 전체 기관의 정답분포와 다르 게 나타나는 경우가 발생하여 정답률이 다소 하락하였다. 이는 정도관리 검체에 따라 장비별로 기질효과가 발생하는 것으로 보이며 이에 대한 추가적인 연구가 필요하였다.

요비중검사는 2017년과 성적과 동일하게 참여기관의 정답 률이 양호하였으나 아직도 결과 입력오류가 발견되었다. 매일 환자의 결과를 입력하는 것처럼 정도관리 결과 입력도 정도관 리의 한 부분이다. 따라서 비정상적인 결과가 입력되지 않도록 각 기관에서는 각별한 주의를 기울여야 할 것이다.

요침사 신빙도조사에서도 2017년 정답률 78.8\%-99.3\%보 다 조금 하향된 성적을 보였다. 2018년에는 비정형 calcium oxalate, 적혈구 원주 등 다소 난이도가 높은 결정체들이 제시 되어 다소 정답률이 낮아진 것으로 생각되었다. 적혈구 원주 는 임상 검체에서 자주 나타나는 침사물이므로 각 기관에서 좀 더 주의를 기울여 잘 판독할 수 있어야 할 것이다. Calcium oxalate 결정은 정상 뇨에서 발견되는 결정으로 보고를 잘 안 하는 경향이 있다. 하지만 소변에서 빈번하게 나타날 경우 요 결석을 형성할 수 있으므로 경검과정에서 발견되면 빠짐없이 보고해야 한다[2,3]. 세뇨관 상피세포와 이행상피세포의 구별 은 매년 출제하고 있지만 한 장의 사진으로 판독이 용이하지 않은 실정이다.

$\mathrm{FOB}$ 정성검사에서는 2016년에 이어 2017년에도 음성 검 체에 대한 위양성률이 높지 않아 국내시약의 질 개선이 이루어 진 것으로 보인다 $[1,4]$. 그러나 $\mathrm{SD}$ 사 및 $\mathrm{GC}$ Genedia 시약에 서는 아직도 음성 검체에 대한 정답률이 $76.4 \%-89.3 \%$ 를 나타 내어 시약 개선이 필요하였다. 두 회사는 2017년에도 음성 검 체에서 $86.2 \%$ 및 $88.9 \%$ 의 정답률을 나타내어 타 회사에 비하 여 $\mathrm{FOB}$ 검사에 대한 위양성률이 높은 것으로 나타났다. 특히 $\mathrm{SD}$ 사 제품은 신빙도조사 참여기관의 $43.9 \%$ 를 차지하고 있어 시약 개선이 시급한 실정이다.
대변잠혈 정량검사에서 Alfresa 장비의 두 가지 모델의 농 도차가 현저하여 Alfresa 장비는 모델별로 분리하여 정답분포 를 분석하였다. Alfresa NS-Plus C 장비는 음성 검체에서 모 두 높은 수치를 나타내었으나, FOB 양성 검체에서는 Alfresa NS-Prime 장비 및 Eiken 장비와 유사한 농도값을 나타내었 다. 따라서 Alfresa NS-Plus C 장비는 대변정량검사에서 위 양성 결과를 도출할 가능성이 높다. NS-Plus C는 2005년에, NS-Prime은 2013년경에 개발되었으며, 각각 27 개 기관과 37 개 기관에서 사용되고 있다[5]. NS-Plus C 장비는 출시된 지 오래되었고 사용하는 기관도 많지 않으므로 이 장비를 사용 하는 기관은 NS-Prime 장비로 교체하는 것이 바람직하였다. Kyowa 장비는 2017년과 유사하게 양성 검체에서 다소 높게 측정되는 경향을 보였다.

Table 7에 제시된 $\mu \mathrm{g} / \mathrm{g}$ stool에 의한 수치는 실제치가 아니 고 장비별로 주입되는 대변 양을 일괄적으로 적용하여 산술적 으로 도출된 수치이다.

\section{REFERENCES}

1. Jeon CH, Lee AJ, Kim SG, Suh HS, Bae YC. Annual report on the external quality assessment scheme for urinalysis and fecal occult blood testing in Korea (2017). J Lab Med Qual Assur 2018;40:128-35.

2. Finkielstein VA, Goldfarb DS. Strategies for preventing calcium oxalate stones. CMAJ 2006;174:1407-9.

3. Laube N, Klein F, Bernsmann F. Kinetics of calcium oxalate crystal formation in urine. Urolithiasis 2017;45:1517.

4. Jeon CH, Lee AJ, Kim SG, Suh HS, Bae YC. Annual report on the external quality assessment scheme for urinalysis and faecal occult blood testing in Korea (2016). J Lab Med Qual Assur 2017;39:117-23.

5. Kim JH, Hwang SY, Kim YJ. Evaluation of Hemo Techt NS-plus C15 Automatic Analyzer for fecal occult blood test. J Lab Med Qual Assur 2010;32:237-41. 